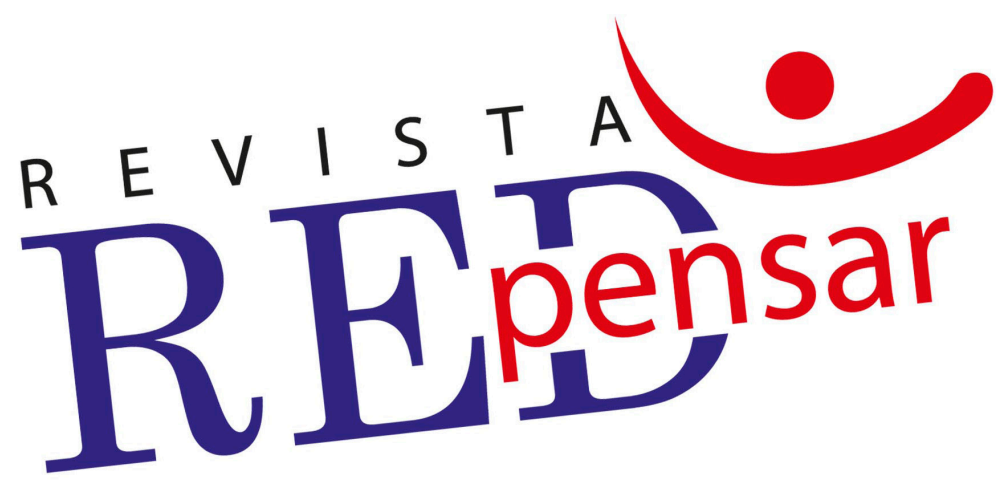

\title{
Recordar y resignificar a Medellín
}

Remember and resignify to Medellin

\section{Sergio Augusto Leal Carreño, fsc}

Revista REDpensar, volumen 6, número 2, Junio-Diciembre 2017 ISSNe: 2215-5384

Revelando otras prácticas 2 Recibido: 01 de octubre de 2018 Aceptado: 31 de octubre de 2018

DOI: 10.31906/redpensar.v6i2.142

\section{(ㄷ)(1) $(2)$}




\section{Recordar y resignificar a Medellín}

\section{Remember and resignify to Medellín}

Sergio Augusto Leal Carreño, fsc ${ }^{1}$

\section{Resumen}

Esta reseña hace memoria de lo acontecido en el III Congreso Continental de Teología Latinoamericana y Caribeña, organizado por Amerindia en El Salvador. Constituyó un encuentro que permitió resignificar las enseñanzas de Medellín, a la luz de los nuevos desafíos que la realidad Latinoamericana y del Caribe plantea. Esta reseña pretende recoger la experiencia del Congreso a través de la descripción de las grandes temáticas abordadas en el mismo, que fueron agrupadas por el autor en: Teología de Medellín, Opción por los pobres, Eclesiología de Medellín, Nuevos areópagos y El Salvador. Finalmente, con el ánimo de ser fiel a lo acontecido en San Salvador, se retoman las conclusiones oficiales del Congreso.

Palabras Clave: MEDELLÍN, OPCIÓN POR LOS POBRES, AMAZONÍA, TEOLOGÍA, ECLESIOLOGÍA.

\section{Abstract}

This review recalls what happened at the III Continental Congress of Latin American and Caribbean Theology organized by Amerindia in El Salvador. Constituted a meeting that allowed to resignify the teachings of Medellín, in light of the new challenges that the Latin American reality and the Caribbean poses. This review aims to collect the experience of the Congress through the description of the major issues addressed in it, which were grouped by the author in: Theology of Medellín, Option for the poor, Ecclesiology of Medellín, New areópagos and El Salvador. Finally, with the intention of being faithful to what happened in San Salvador, the official conclusions of the Congress are retaken.

Keywords: MEDELLÍN, OPTION FOR THE POOR, AMAZONIA, THEOLOGY, ECCLESIOLOGY

\section{Introducción}

La segunda Conferencia General del Episcopado Latinoamericano constituyó un renacer de la Iglesia en América Latina, "marcado por una profunda renovación espiritual, por una generosa caridad pastoral, por una auténtica sensibillidad social” (Brendao, 1968, p.8). Según los expertos, esta Conferencia no sólo constituyó la traducción del Concilio Vaticano II a la realidad de este continente, sino por sobretodo la recepción y contextualización creativa del mismo en un continente de desigualdades, de aumento de toma de conciencia, o en palabras más abrasadoras, fue el Concilio de América Latina.

1. Hermano de La Salle. Licenciado en Educación Religiosa de la Universidad De La Salle de Bogotá-Colombia y Administrador de Empresas de la Universidad Externado de Colombia. Actualmente labora como Secretario Regional de Gestión y Organización de la Región Latinoamericana Lasallista - RELAL. Correo electrónico: sergioleal@,relal.org.co 
El objetivo de esta reseña es hacer memoria del acontecimiento vital que fue Medellín para América Latina y resignificarla a partir de la actualización de sus propuestas a la realidad este continente. La metodología que se utilizó está basada, en primera medida, en la participación en el Congreso, por lo cual se resalta el aspecto vivencial del mismo, es decir, el hecho de escuchar diferentes posturas y experiencias; y en segunda medida en la consulta de algunos autores que han coadyuvado a esa resignificación de Medellín, tales como Leonardo Boff, Cecilio de Lora, Paulo Freire y, por supuesto, el Papa Francisco.

Con la fuerza y el fuego abrasador de Medellín², cualquier esfuerzo por retomar sus palabras, textos, invitaciones, exhortaciones y hasta mandatos, es muy bien recibido por la comunidad teológica de América Latina. Es precisamente en esta dinámica que Amerindia ${ }^{3}$ convocó en este año en San Salvador - El Salvador, al III Congreso Continental de Teología Latinoamericana, cuyo lema fue "Los clamores de los pobres y de la tierra nos interpelan”, a 50 años de Medellín. Un encuentro vital en donde seglares, religiosos y sacerdotes de toda América Latina y el Caribe, incluso también de América del Norte y de Europa, se reunieron durante cuatro días para recordar y resignificar la fuerza de Medellín, pero también para volver a cargar de esperanza y compromiso en continuar con la lucha por una Iglesia que sea solidaria con los pobres, con la tierra y su integridad.

Este Congreso permite recordar las palabras de Paulo Freire cuando intenta definir a un maestro:

El maestro es, necesariamente, militante político. Su tarea no se agota en la enseñanza de las matemáticas o la geografía. Su tarea exige un compromiso y una actitud en contra de las injusticias sociales [...]

El maestro debe caminar con una legítima rabia, con una justa ira, con una indignación necesaria, buscando transformaciones sociales. (Freire, 1993, 100-130).

La conferencia de Medellín continúa siendo para la Iglesia Latinoamericana una maestra, como la entiende Freire, ya que ella:

a. Recuerda a la Iglesia su ser comunidad narrativa: haciendo memoria de nuestra identidad, desde el primer testamento hasta hoy. Nuestra identidad como cristianos es inseparable de la imagen de Jesús como profeta. Es una memoria peligrosa.

b. Es un documento fundacional, matriz, pues con ella nace la iglesia con rostro latinoamericano y caribeño.

c. Por su modo de producción motiva al profetismo original, ya que logra recoger el valor profundo de las prácticas sociales, pastorales y teológicas que ya estaban haciéndose en nuestro continente, para exponerlas en conjunto de la Iglesia.

El III Congreso Continental de Teología Latinoamericana se articuló a partir de una serie de conferencias magistrales, testimonios, mesas temáticas y experiencias, de las cuales se rescatan, a través de categorías, algunos elementos significativos:

\footnotetext{
2. Al hablarse de Medellín, se hace referencia resumida de la Segunda Conferencia General del Episcopado Latinoamericano, llevada a cabo en la ciudad de Medellín - Colombia, del 29 de agosto al 07 de septiembre de 1968.

3. Amerindia se define como una red de católicos con espíritu ecuménico, abierto al diálogo y a la cooperación interreligiosa con otras instituciones. Se propone, como prioridad, reafirmar la opción preferencial por los pobres y excluidos, inspirada en el Evangelio, actualizando la herencia de las Conferencias Generales del Episcopado Latinoamericano en Medellín (1968), Puebla (1979), Santo Domingo (1992), y Aparecida (2007), así como del Sínodo de América (1997), para responder a los nuevos desafíos planteados a nuestros países por la globalización neoliberal. Esto implica reafirmar la opción por nuevos modelos de iglesia comunitaria y participativa y por la Teología de la liberación como un aporte a la iglesia universal.
} 


\section{Teología de Medellín}

La teología de América Latina se ha caracterizado por su frescor y vitalidad, además de su profunda reflexión. Medellín no fue la excepción, con una reflexión teológica en que la fe y la justicia son un binomio inseparable, puesto que "la fe, si no tiene obras, está muerta en sí misma" (Santiago 2,14). Es en esta perspectiva que Medellín asume que su mayor urgencia es la opción por las personas pobres, pero no como una ideología (marxista o comunista), sino como una mística del encuentro con Dios en el rostro del pobre.

Entonces, la propuesta de Medellín radica en la invitación a vivir una actitud teológica de contemplación activa, de mística liberadora; en la cual la mística presupone apertura y obediencia al querer de Dios (del cual unos son responsables por otros), de manera que lo místico y lo político se complementan eficientemente. Desde esta perspectiva, la mística ya no será principalmente un aislamiento, sino una actitud alerta y vigilante para ver la realidad y transformarla, viviendo delante del Señor en solidaridad con los pueblos.

Esta teología surgida de Medellín es el producto de un movimiento mundial que se presentó antes de esta conferencia, el cual impulsaba la horizontalidad de las relaciones en la Iglesia y la mística popular, entendida ésta como el conjunto de expresiones colectivas a partir de la experiencia que brota de lo íntimo del corazón ante los hechos cotidianos del pueblo.

Este ethos teológico de Medellín continúo la consolidación de la espiritualidad cristiana, caracterizada por la encarnación del espíritu, por su abajamiento y por las manifestaciones de la religiosidad popular. En esta dinámica es posible afirmar que la religión del pueblo latinoamericano es el repositorio de la teología.

Finalmente, desde esta perspectiva teológica, el teólogo está llamado a mantener viva la historia subversiva de las víctimas, es convocado a vivir la compasión hasta las últimas consecuencias, haciendo posible la salvación del hombre, que en palabras de Populorum Progressio, "es el paso de condiciones de vida menos humanas a condiciones de vida más humanas” (Pablo VI, 1967, párrafo 20).

\section{Opción por los pobres}

Sin duda la centralidad del pobre fue un aspecto esencial en Medellín, el cual fue retomado prodigiosamente por las diferentes conferencias y testimonios del Congreso, recordando las palabras del Padre Cecilio de Lora (2011) "no se trata de optar por los pobres para aumentar su número, sino para salir con ellos de la pobreza, luchando contra la injusticia" (De Lora, 2011, p.1239).

La opción por lo pobres en Medellín parte de la experiencia bíblica, que nos recuerda que el amor de Dios para con los pobres es el mismo que el padre tiene por el hijo pródigo. Es un amor incondicional, gratuito y comprometido. Este punto de partida se concreta en la opción preferencial de Jesús por los más pequeños, entre ellos los pobres, excluidos, sin tierra. Jesús nos invita a dejarnos interpelar por la fuerza de los más pobres y los más pequeños.

Este camino de solidaridad con los pobres acompaña todo el caminar de la iglesia, que se coloca en el centro del seguimiento de Jesús, a partir de una mística comprometida con el pobre. También en el hecho de sentir compasión, puesto que la Iglesia no puede ser sorda ni muda ante el clamor de los pobres.

Hoy por hoy, debemos estar atentos en cada tiempo y lugar a los gritos y resistencias de los pobres, descubriendo los signos del Espíritu, que sopla "desde abajo" y comprometernos a ayudarlos a ser los artesanos de su misma liberación y salvación, es decir, de su itinerario de humanización.

\section{Eclesiología de Medellín}

Otro tema central del Congreso fue la eclesiología que nació a partir de Medellín, la cual nos presenta a la Iglesia como una iglesia pobre, unida a la causa de los pobres, preocupada por los pobres, para los pobres; 
es decir, la iglesia de Jesús de Nazaret. Entonces, la eclesiología que impulsa Medellín tiene una clara exhortación hacia quiénes se debe dirigir la mirada cuando se habla, se piensa y se construye Iglesia, es decir, cuál es el criterio de discernimiento: desde el lugar del pobre (De La Salle, 2003, p. 14).

Esta eclesiología ha sido retomada constantemente por el Papa Francisco, espacialmente cuando hace referencia a una "Iglesia en salida hacia las periferias". Cabría preguntarnos con Boff (2015): ¿qué implica una Iglesia en salida?:

- Salida de una Iglesia-fortaleza.

- Salida de una Iglesia-institución absolutista.

- Salida de una Iglesia-jerarquía.

- Salida de una Iglesia-autoridad eclesiástica.

- Salida de una Iglesia-Papa de todos los cristianos y obispos.

- Salida de una Iglesia-maestra de doctrinas y normas.

- Salida de una Iglesia-de poder sagrado, de pompa y circunstancia.

- Salida de la Iglesia-que habla de los pobres.

- Salida de una Iglesia-equidistante de los sistemas políticos y económicos.

- Salida de una Iglesia-automagnificadora y acrítica.

- Salida de una Iglesia-del orden y del rigorismo.

- Salida de una Iglesia-de devotos.

- Salida de una Iglesia-obediencia y de la reverencia.

- Salida de una Iglesia-sin el mundo que permitió que surgiese un mundo sin Iglesia.

De esta manera se exhorta a superar el narcisismo de la Iglesia, la autorreferencialidad, para volver a centrarse en la acción de Dios, no mirando desde afuera, sino desde dentro, desde la propia problemática, en los que somos parte del problema que tenemos que atender, que nuestro ver, juzgar y actuar no sea de los otros, sino desde nosotros mismos. En otras palabras, se anima a la Iglesia a mirar de frente la realidad latinoamericana en vez de mirarse a sí misma.

Un aspecto importante es que Medellín termina con la imagen de una Iglesia uniforme, devolviendo a las iglesias locales el valor teológico que tienen, puesto que la iglesia local no es una sucursal de la iglesia central, sino que es la iglesia toda en un lugar específico, desde una consideración teológica-pastoral. En Medellín la iglesia deja de ser iglesia reflejo para ser iglesia fuente, en salida, martirial, integral, ética, solidaria y cuidante.

\section{Nuevas areópagos}

El Congreso también permitió realizar actualizaciones de los nuevos lugares teológicos de opción por los pobres e intervención social, los cuales fueron:

- Mundo de los jóvenes.

- Organizaciones/ Movimientos populares y sociales.

- Partidos políticos de izquierda.

- Articulación local y mundial de las redes.

- Lucha LGBT.

- Feminicidios.

- Violencia en las periferias.

- Amazonía.

Por su relevancia y significado se hará referencia al último lugar teológico, la Amazonía, que está conformada por aproximadamente 34 millones de personas, se ubica en el centro de sur América e involucra a 9 países: Bolivia, Perú, Venezuela, Ecuador, Colombia, Brasil, Guyana, Guayana Francesa y Surinam. Este lugar conforma un bioma sumamente rico en fauna y flora, se destacan algunos datos 
importantes ${ }^{4}$ :

- El Bioma amazónico tiene un papel en el ciclo de las aguas. Sin la Amazonia buena parte de Suramérica sería un desierto. Cada árbol de la Amazonia inyecta en el aire cerca de mil litros de agua todos los días, formando un río aéreo que hace llover en el continente. También las aguas subterráneas del Amazonas son muy grandes.

- El ciclo del carbono se afecta cuando cada árbol es derribado o quemado.

- Es la región más biodiversa del mundo, en $1 \mathrm{~m} 2$ de Amazonia hay más diversidad que en Estados Unidos de América, Canadá, Rusia o China. De aquí dependen muchas cadenas productivas de alimentos, fármacos, esencias, cosméticos.

El Papa Francisco considera la Amazonia como un lugar teológico, un lugar donde Dios habla, y por esto hace una invitación explícita a cuidarla. A pesar de reconocer el gran trabajo que la Iglesia realiza en la Amazonía, considera que no es suficiente, puesto que todo está interconectado y requiere la intervención y el cuidado. Por esto considera que las luchas sociales y ambientales van de la mano, y que es necesario juntar las fuerzas para el trabajo en la Amazonía. En sintonía con esta reflexión el Papa ha convocado un Sínodo acerca de la Amazonía, que es considerado un signo de los tiempos, puesto que "el destino de la humanidad está interconectado con el destino de la Amazonia, pues todo lo que sucede con la Amazonia también va a suceder con la humanidad".

Finalmente, la defensa de la Amazonia no es solamente un gesto de solidaridad para con una región de Latinoamérica, puesto que el hombre depende de la existencia de la Amazonia para sobrevivir. Es también un problema ecuménico, de las iglesias, no sólo de la iglesia católica.

\section{El Salvardor}

En este último apartado se menciona lo que significa el lugar en el que se desarrolló el III Congreso de Teología Latinoamericana: El Salvador. Fue este país sede del Congreso, pero también lugares tan significativos como la Universidad Centroamericana “José Simeón Cañas" [UCA] y la capilla del Hospital Divina Providencia, en donde ocurrieron los martirios de Ignacio Ellacuría junto con sus compañeros jesuitas y las dos señoras del servicio, y de Monseñor Oscar Romero, respectivamente.

Fue una experiencia mística el hecho de estar en cada uno de estos dos lugares, tener un espacio para escuchar testimonios de personas que compartieron con estos dos grandes religiosos entregados a la causa del pueblo salvadoreño. Sin duda, un momento de kairós que hizo realidad en los participantes del Congreso la vivencia mística de un encuentro.

Aunque cabe anotar que El Salvador fue y sigue siendo epicentro de profundas desigualdades sociales y económicas, además de persecución e injusticia, es también un lugar de profunda mística cristiana, donde la Iglesia fue una Iglesia martirial, Iglesia Latinoamericana, o en palabras de Monseñor Romero, una Iglesia de los Pobres.

Por último, hablar de Iglesia Salvadoreña es hacer referencia a Oscar Romero, de quien dicen los más sencillos ${ }^{5}$ "Monseñor Romero dijo la verdad, nos defendió a los pobres y por eso lo mataron" (Sobrino y Zechmeister, 2018). Fue poseedor de la verdad, diciéndola como Evangelio y como denuncia. Dejó que la verdad tomara la palabra. Para Romero decir la verdad era defender al pobre, por lo cual son recordadas aún las palabras que pronunció el 23 de marzo de 1980 “en nombre de Dios, pues, y en nombre de este sufrido pueblo, cuyos lamentos suben hasta el cielo cada día más tumultuosos, les suplico, les ruego, les ordeno en nombre de Dios: ¡cese la represión!" Por esto, cobran sentido las palabras de Ignacio Ellacuría "con Monseñor Romero, Dios pasó por El Salvador".

4. Información tomada del Conversatorio "El grito panamazónico reclama un nuevo rostro de Iglesia" a cargo de Mauricio López y Roberto Malvezzi.

5. Información tomada de la conferencia "El legado de Monseñor Romero", a cargo de Jon Sobrino. 


\section{Conclusiones}

Finalmente, a manera de conclusiones me permito colocar las siete premisas con las cuales Amerindia concluyó este Congreso:

- Insertarse en la historia, en el mundo de los pobres, para que seamos capaces de leer los signos de los tiempos desde allí.

- Esta inserción debe estimular praxis liberadoras en las que los pobres han de ser sujetos de su liberación, teniendo en cuenta la importancia de la memoria histórica, profética y martirial de las Iglesias locales.

- El lugar propio de la memoria histórica es la comunidad. Es ahí donde se impulsan experiencias alternativas y nuevos ministerios, como servicios generadores de relaciones horizontales, como signo de la igualdad fundamental de todos los cristianos.

- El tener en cuenta que lo más importante es la praxis de liberación, significa asumir el método inductivo e histórico en la producción teológica liberadora.

- Es necesario escuchar el grito de la tierra en los gritos de los pobres, aprendiendo de la sabiduría indígena e inspirándonos en ella para encontrar nuevas formas de organizar la vida: más humana y espiritual, más solidaria y profunda.

- Es urgente reafirmar lo esencial frente a un mundo convulsionado, desarrollando una mística liberadora que nos ayude a percibir las huellas del Espíritu en la historia.

- Mantener vivo el espíritu de Medellín que, al impulsar una recepción creativa del Concilio Vaticano II, significó un nuevo Pentecostés para la Iglesia latinoamericana. A la luz de este acontecimiento, verdadero parteaguas en la historia de la Iglesia en este continente, seguir buscando los nuevos caminos por donde el Espíritu quiera guiarnos.

\section{Referencias Bibliográficas}

Boff, L. (2015). Papa Francisco: Iglesia en salida, ¿de dónde y hacia dónde? Recuperado de: http:// www.servicioskoinonia.org/boff/articulo.php? num $=715$

De La Salle. (2003). Horizonte Distrital de la Formación. Distrito Argentina-Paraguay. Recuperado de https://bit.ly/2SDpFPJ

De Lora, C. (2011). Del Concilio a Medellín, hoy. Revista Latinoamericanas-Artigo. 9(24), 1233-1245. doi: $-10.5752 /$ P.2175-5841.2011v9n24p1233

Freire, P. (1993). Cartas a quien pretende enseñar. Buenos Aires, Argentina: Siglo XXI Editores.

López, M. y Malvezzi, R. (2018). El grito panamazónico reclama un nuevo rostro de iglesia. III Congreso Continental de Teología Latinoamericana y Caribeña. Conferencia llevada a cabo en Universidad Centroamericana “José Simeón Cañas", de San Salvador.

Pablo VI. (1967). Carta Encíclica Populorum Progressio. Ciudad del Vaticano: Libreria Editrice Vaticana. Recuperado de bttps://bit.ly/1NuTucp

Sobrino, J. y Zechmeister, M. (2018). El legado de Monseñor Romero. III Congreso Continental de Teología Latinoamericana y Caribeña. Conferencia llevada a cabo en Universidad Centroamericana "José Simeón Cañas", San Salvador, El Salvador. 